THE

VETERINARY

CLINICS

Vet Clin Equine 18 (2002) 411-437

Equine Practice

\title{
Managing chronic arthritis
}

\author{
Erin D. Malone, DVM, PhD \\ Department of Clinical and Population Sciences, 225K Veterinary Teaching Hospitals, \\ 1365 Gortner Avenue, St. Paul, MN 55108, USA
}

Managing joint disease is a common requirement for owners of older horses. Needs range from keeping broodmares comfortable on pasture to maintaining dressage horses in performance. This article touches on the various treatment and control modalities available and discusses documented usefulness and potential side effects for the older horse.

Cartilage damage is the hallmark of osteoarthritis; however, in most instances, cartilage damage is accompanied by changes in the joint capsule, synovium, and subchondral bone. Treatment protocols need to consider all components to be optimally effective. Primary treatment goals include control of pain, maximizing function, limiting disease progression, and, at least theoretically, facilitating repair processes [1].

\section{Pain management}

Pain is commonly associated with equine osteoarthritis. Chronic pain has little or no protective value and can alter nervous system responses, which results in physiologic, metabolic, and immunologic changes if not controlled [2]. Inflammation also leads to hypersensitization to stimuli, with decreased activation thresholds and recruitment of additional nociceptive fibers [3].

Nonsteroidal anti-inflammatory drugs (NSAIDs) are the most commonly used analgesic drugs in the horse. Besides controlling pain by inhibiting prostaglandin release, they most likely have central actions not related to cyclooxygenase [4]. NSAIDs and other anti-inflammatory agents are discussed below. NSAIDs are considered to be only moderately effective at controlling the painful response to osteoarthritis, however. Enhanced responses may be obtained with the addition of other therapies.

E-mail address: malon001@tc.umn.edu (E.D. Malone). 


\section{Arthroscopy}

Although arthroscopy is highly useful for evaluating the extent of cartilage damage in equine joints, it is often less valuable as a therapeutic tool. Osteophyte removal is usually not necessary unless the bony proliferations impinge on an articulating surface or are at risk of fracture [5]. Conservative debridement of abnormal cartilage is recommended because of its poor healing capability [6]. Synovectomy theoretically allows removal of a major source of inflammation. When performed experimentally in horses, the regenerated synovium was devoid of villi and had abnormal architecture. No detrimental cartilage effects were detected by 120 days [7]. Preliminary work in horses with synovitis suggests that it may stimulate cartilage remodeling, however [8]. In people, synovectomy is more commonly used for chronic hemarthrosis and rheumatoid arthritis than for osteoarthritis. Improvement rates for nonrheumatoid arthritis still approach 50\% unless severe bone destruction is present [9]. Manual synovectomy is being replaced with radiation or chemical synovectomy in many situations $[10,11]$.

\section{Arthrodesis}

Arthrodesis is a viable option for movement-related pain, particularly in the pastern joints and lower hock joints. Fusion of these joints does not preclude athletic performance. A pastern joint may be fused using cortical screws, dynamic compression plates, or a combination of screws and plates $[12,13]$. Reported success rates for return to performance range from $46 \%$ to $67 \%$ in forelimbs to $80 \%$ to $84 \%$ in hind limbs $[13,14]$. Recovery times average 10 months before return to work [13]. In one study, four of six horses with bilateral pastern arthrodeses were able to return to work [13].

Fusion of the distal intertarsal and tarsometatarsal joints can be accomplished naturally by continuing work and/or intra-articular corticosteroids. This process is usually lengthy, however, and fusion may not occur [15]. The fusion process can be enhanced with the use of cartilage removal by intraarticular drilling or by injection of monoiodoacetate (MIA). Intra-articular drilling does not remove all cartilage but does allow enough bony union to occur so as to improve lameness. Functional ankylosis is apparent at 3 to 8 months, and horses are usually back in regular work at 6 to 12 months $[16,17]$. The procedure may be combined with a cunean tenectomy, which may also help with pain relief [16]. A $78 \%$ to $80 \%$ success rate for return to soundness is reported for treatment of the lower joints [16,17]. Horses with proximal intertarsal joint osteoarthritis do not respond as well $(55 \%)$ [17]. Implants (eg, T-plates, perforated stainless steel cylinders) or grafts may be added; the convalescence period has not been shown to be altered, but success rates may be slightly improved [17,18]. In many instances, subchondral fenestration is also performed at the time of surgery. This may enhance pain relief if elevated subchondral bone pressures are present [19]. 
MIA injection is reportedly a relatively easy and inexpensive method of fusion. The compound destroys cartilage by causing chondrocyte death. In a report involving 39 horses, $70 \%$ of horses were fused by 3 months and $63 \%$ were sound at that time. By 12 months, $88 \%$ were fused and sound. Long-term (mean $=28$ months), $75 \%$ were sound [20]. Problems developed in the proximal intertarsal joint and tarsocrural joint in 4 horses, perhaps as a result of inadvertent MIA injection of the proximal intertarsal joint. The recommended protocol involves injection of $100 \mathrm{mg}$ of MIA after a contrast arthrogram to confirm needle placement and lack of joint communication. Postinjection pain is severe, and horses need appropriate pain control for the first 12 to 18 hours but then seem to return to preinjection levels of lameness. After the initial pain resides, horses should be exercised for 1 to 2 weeks to encourage maceration of cartilage. Stall rest is then recommended for 1 to 2 months, and turnout should be restricted until 4 to 6 months after injection.

Arthrodesis of the fetlock joint, coffin joint, or carpus is possible but is generally restricted to salvage animals for breeding purposes or for pasture retirement. Successful fusion of the scapulohumeral joint was reported in a miniature stallion [21].

\section{Exercise}

Consistent light exercise regimens are recommended and may improve range of motion and muscle strength [22]. Pasture turnout is preferred over stall rest, because stall rest generally results in increased stiffness and pain. Stall rest should be used only during periods of acute pain exacerbation or joint instability [1]. Exercise that strains joints excessively or that persists for extended periods should be avoided but light to moderate exercise stimulates articular chondrocyte metabolism [23]. Body weight should be reduced to normal or slightly lighter levels to minimize mechanical stress [1].

\section{Shoeing}

In people, shock-absorbing footwear reduces impact and pain [22]; pads may provide some benefit in horses with joint pain. Horses with hind limb problems do better without calks, stickers, or trailers, which can torque the limb [16]. Well-fitting wide web shoes with an adequate heel distribute weight. Flexion of the joint stretches the joint capsule, increases intra-articular pressure, and even increases intramedullary pressure, all of which leads to exacerbated pain [4]. Therefore, easing breakover with short foot length, squared off toes, or rocker-toed shoes may help horses with osteoarthritis [24]. More frequent trimming (every 4-6 weeks) is often beneficial to maintain short foot length.

\section{Acupuncture}

People with osteoarthritis tend to be one of the groups with the highest acupuncture use rate [22]. In a review on the various trials evaluating the use 
of acupuncture to treat equine lameness, improvement was noted in $82.4 \%$ of horses with back pain, $87.5 \%$ of horses with shoulder pain, $94.1 \%$ of horses with fetlock pain, and $86.7 \%$ of horses with laminitis. In most cases, two to five treatments were recommended, with treatments scheduled 1 to 4 weeks apart [25]. The quality of trials was not addressed. A review of the human literature found inconclusive evidence for change in function but improvement in pain management [26]. Strong placebo effects and difficulty in masking were noted [22]. In a recent human study, positive effects on pain lasted 4 weeks after acupuncture treatment [27].

\section{Magnetic therapy}

Both static and pulsating electromagnetic field therapies have been suggested to provide analgesia. The reports on pulsating fields in people are conflicting; a summary study suggested that insufficient data are available to draw conclusions as to efficacy [28]. Static magnetic field studies have similar mixed results [29]. Recent studies have demonstrated decreases in pain and synovitis $[30,31]$. In horses, blankets and boots are available to provide pulsating electromagnetic fields; however, it is difficult to select a field strength appropriate for a particular disorder [29]. Static fields are easier to obtain using relatively inexpensive magnet-containing pads and wraps. There are no studies verifying the efficacy of either form for equine osteoarthritis.

\section{Transcutaneous electric nerve stimulation}

Electric muscle stimulation using pulsed alternating current enhances muscle strength and joint flexibility as well as decreasing pain and edema [32]. Transcutaneous electric nerve stimulation (TENS) units are primarily designed for pain relief rather than for muscle strengthening [32]. Two recent reviews of the literature suggest that TENS may be helpful for people with osteoarthritis, but no reports of well-controlled pain studies in animals have been published $[33,34]$.

\section{Therapeutic ultrasound}

Therapeutic ultrasound is primarily used for tendinous injuries and soft tissue scarring. It could help to relieve joint contracture before exercise; however, this has not yet been effectively demonstrated [28,35]. By heating tissues, it increases blood flow and decreases pain as well as increasing tissue extensibility [32]. In chronic injuries, the continuous mode is preferred because of its thermal effects [32]. Potential exists for phonophoresis or sonophoresis, the use of ultrasound to transmit drugs through skin as discussed below [35].

\section{Low-level laser therapy}

Laser therapy is used for pain relief and has been shown to decrease the pain associated with knee osteoarthritis in people; twice-daily treatments for 
10 days resulted in effects lasting 4 to 6 months [28]. Difficulties exist in determining appropriate wavelength, dosage, and treatment duration [36]. The mechanism of action is unknown, and controlled veterinary studies are lacking.

\section{Capsaicin}

Capsaicin, a component of hot peppers, excites C-fibers, leading to the release and subsequent depletion of substance $\mathrm{P}$ from afferent nerves. Prolonged exposure leads to analgesia because of lack of neurotransmitter [37]. Pain scores and analgesic use subsequently decrease [37,38]. In people, capsaicin is applied four times daily for the treatment of osteoarthritis. Efficacy was increased and an initial burning sensation was decreased when capsaicin was combined with glyceryl trinitrate [38].

\section{Extracorporeal shockwave therapy}

Extracorporeal shockwave therapy (ESWT) is used in people for insertional desmopathies, periosteal inflammation, and bone exostoses [39]. In horses, it has been reported to be useful for suspensory desmitis, navicular syndrome, splint bone exostoses, capsulitis, bone spavin, and check ligament desmitis $[39,40]$. Convincing studies are still lacking in human and equine medicine, however, as are data on ideal treatment parameters and source of shockwaves [41].

\section{New analgesics}

Newer opioids with minimal central nervous system (CNS) and gastrointestinal (GI) effects are being developed and may be useful in the horse. Tramadol is a synthetic oral opioid that is being used in people who do not respond to treatment with NSAIDs for osteoarthritis [22]. Tramadol is effective epidurally in horses [42]. An opioid antagonist is also being developed that seems to be capable of preventing GI effects without altering the analgesic properties of morphine [43].

Other drugs are being investigated in people and animals for newly discovered analgesic effects. These include tricyclic antidepressants, such as amitriptyline and imipramine, given at a lower dose and shorter time frame than would be used for clinical depression. They are associated with significant side effects, however [44]. Gabapentin is a newer anticonvulsant that is being suggested as a useful analgesic in cats [45]. $N$-methyl-D-aspartate (NMDA) receptor antagonists (related to dextromethorphan) and leukotriene $\mathrm{D}_{4}$ receptor antagonists are also being investigated $[44,46]$.

\section{New delivery routes}

Avoidance of painful intra-articular injections is an area of extensive research. Methods of transdermal drug delivery are described below. Recent 
reports suggest that subcutaneous hydromorphine is equivalent to intramuscular meperidine for controlling postoperative pain with fewer side effects [47]. Additionally, an implantable drug delivery device has been described [48]. Fentanyl patches hold promise for chronic pain management in horses [49]. A lidocaine patch is being developed, as are carriers designed to prolong local anesthetic effects [50-52].

\section{Control of inflammation}

Normal articular cartilage is relatively acellular and is composed primarily of a hyperhydrated matrix that provides compressive strength and a network of collagen fibers that provides both tensile strength and architectural support [53]. The matrix consists of proteoglycans joined to long backbones of hyaluronan. The proteoglycans are composed of glycosaminoglycans (GAGs), highly negatively charged chains of repeating disaccharides bound to a protein core. The strong anionic nature of the GAGs allows the matrix to contain $65 \%$ to $80 \%$ water [54]. Collagen fibers (primarily type II) bind both the proteoglycans and the subchondral bone [53].

Matrix turnover is slow, and many factors can overwhelm the reparative capabilities of hyaline cartilage. Abnormal stresses (eg, instability caused by soft tissue or bone damage) can directly damage the collagen framework (leading to release of proteoglycans) or cause chondrocyte injury (leading to decreased proteoglycan production). Inflammation causes the release of enzymes that can degrade proteoglycans, hyaluronan, or collagen as well as decrease the synthesis of matrix components. With decreased proteoglycan content, cartilage cannot retain as much water and is more easily damaged.

Synovitis is an almost universal component of osteoarthritis in horses. In many instances, it is likely the initiating factor and is usually more closely correlated with clinical signs than is the amount of cartilage damage [3]. Release of lysosomal enzymes and production of inflammatory mediators, such as prostaglandin $\mathrm{E}_{2}\left(\mathrm{PGE}_{2}\right)$, interleukin-1 and interleukin-2, tumor necrosis factors, and neutral matrix metalloproteinases, contribute to cartilage breakdown, ongoing synovitis, and pain [53,55]. Anti-inflammatory drugs, such as NSAIDs, corticosteroids, and sodium hyaluronate (HA) help to protect cartilage by reducing inflammatory enzymes and the associated matrix degradation and decreased matrix synthesis [56].

\section{Nonsteroidal anti-inflammatory drugs}

Phenylbutazone is the most widely used of the NSAIDs, with doses of 2.2 $\mathrm{mg} / \mathrm{kg}$ or less being relatively nontoxic long-term [57]. In a model of acute synovitis, phenylbutazone $(4.4 \mathrm{mg} / \mathrm{kg})$ was found to be better at reducing lameness, joint temperature, synovial fluid volume, and synovial fluid $\mathrm{PGE}_{2}$ than was ketoprofen ( 2.2 or $3.63 \mathrm{mg} / \mathrm{kg}$ ) [58]. Phenylbutazone is inexpensive and readily available in either paste or tablet form $(1 \mathrm{~g}$ or $100 \mathrm{mg})$. 
Ketoprofen $(3.63 \mathrm{mg} / \mathrm{kg})$ was more effective at reducing chronic pain caused by laminitis than was phenylbutazone $(4.4 \mathrm{mg} / \mathrm{kg})$, with effects being present for at least 24 hours in three of four tests [59]. Flunixin meglumine has also been shown to be useful for the treatment of lameness but is used less often for economic reasons [60]. Ketoprofen $(2.2 \mathrm{mg} / \mathrm{kg})$ was less toxic than either phenylbutazone $(4.4 \mathrm{mg} / \mathrm{kg})$ or flunixin meglumine $(1.1 \mathrm{mg} / \mathrm{kg})$ when given intravenously (IV) every 8 hours for 12 days [61]. It may also be given safely intramuscularly (IM) [62].

Many other NSAIDs are being investigated in the horse. Ibuprofen is in use clinically for chronic musculoskeletal disorders at 10 to $25 \mathrm{mg} / \mathrm{kg}$ every 8 to 12 hours. Long-term toxicity at this dose has not been evaluated [63]. Eltenac at $0.5 \mathrm{mg} / \mathrm{kg}$ IV once daily for 3 days resulted in significant improvements in joint circumference, range of motion, and stride length in an experimental carpitis model [64]. No difference was detected between 0.5and $1.0-\mathrm{mg} / \mathrm{kg}$ doses, and effects were equivalent to those of flunixin meglumine $(1.1 \mathrm{mg} / \mathrm{kg})$. Analgesic effects of eltenac $(1.0 \mathrm{mg} / \mathrm{kg})$ seem to last 24 hours [65]. Meclofenamic acid (2.2 $\mathrm{mg} / \mathrm{kg}$ every 24 hours) has been found clinically useful in the treatment of musculoskeletal problems in horses, with a $60 \%$ response rate reported for horses with chronic osteoarthritis (compared with $36 \%$ for phenylbutazone) [66]. It has a slower onset of action, however, with 36 to 96 hours being required to detect improvement [66]. Naproxen $(5.5 \mathrm{mg} / \mathrm{kg})$, suxibuzone $(7.5 \mathrm{mg} / \mathrm{kg})$, carprofen $(0.7 \mathrm{mg} / \mathrm{kg})$, and nabumetone $(3.7 \mathrm{mg} / \mathrm{kg}$ ) may prove useful but have not been well evaluated for efficacy against equine musculoskeletal pain [67-70].

Tested NSAIDs have been found to accumulate in areas of inflammation and have increased penetration into inflamed joints; additionally, serum concentrations do not necessarily correlate with clinical response [71,72]. Reduced absorption and delayed time to peak plasma concentration were reported when phenylbutazone was given orally after feeding [73]. If given once daily, morning treatment is probably more effective. The bioavailability of ibuprofen paste was not affected by feeding [74]. When phenylbutazone $(2.2 \mathrm{mg} / \mathrm{kg})$ and flunixin meglumine $(1.1 \mathrm{mg} / \mathrm{kg})$ were given in combination, the pharmacologic effect was prolonged without evidence of changes in disposition or clearance [75]; however, toxicity would also be expected to be additive.

Older horses may be more susceptible to NSAID toxicity. In people, risk factors for upper GI bleeding include age of 65 years or older [22]. This is also true for reversible renal failure. Older ponies (8-10 years old) were found to have a longer half-life of phenylbutazone compared with 3-yearold ponies [76]. The lowest effective dose and longer intervals between doses should be used, especially in debilitated animals. Many animals can be maintained on $2.2 \mathrm{mg} / \mathrm{kg}$ once daily as long as other factors (ie, hoof trimming) are addressed.

Recent studies have suggested that NSAIDs may contribute to joint dysfunction if given long term or at high doses. Some NSAIDs have been found 
to affect articular cartilage metabolism negatively or to increase levels of catabolic cytokines in vitro, probably as a result of changes in the balance of regulatory prostaglandins and leukotrienes [77]. Flunixin meglumine, tolfenamic acid, and ketoprofen increased interleukin-1 activity by equine synoviocytes, whereas phenylbutazone was found to decrease proteoglycan synthesis in cartilage explants, but only at higher concentrations [77,78]. When combined with other changes in the joint environment (eg, decreased $\mathrm{PGE}_{2}$ levels) along with improvements in inflammation and movement, purported side effects may not be clinically significant, however. Long-term NSAID use has not been associated with accelerated disease in human beings [1]. Additionally, some NSAIDs have been found to have minimal effects, at least on normal cartilage [79].

\section{Intra-articular corticosteroids}

Corticosteroids are also commonly used to provide relief from pain and inflammation. They not only inhibit $\mathrm{PGE}_{2}$ formation but decrease neutrophil activation and lysosomal enzyme release; inhibit metalloproteinase activity; block induction of nitric oxide synthase; and decrease vasodilation, edema formation, and fibrin deposition [80]. Intra-articular corticosteroids are considered to be among the most potent and cost-effective treatments available for joint inflammation [81]. The primary corticosteroids used intra-articularly include methylprednisolone acetate, triamcinolone, and betamethasone. Betamethasone has a relatively short duration of action but is potent. Depending on the size of the joint, 3 to $9 \mathrm{mg}$ of betamethasone is typically used [81]. Triamcinolone is also relatively short acting, being undetectable by 15 days after injection; however, its clinical duration of action is generally considered longer [80]. It is favored in high-motion joints at low dosages (3-12 mg per site) [81]. Methylprednisolone acetate tends to be used in low-motion joints, such as the distal hock joints. Amounts range from 40 to $80 \mathrm{mg}$ per site. It is thought of as long acting, but recent reports suggest that it is variably metabolized in the joint (active form undetectable within 5-39 days) [80]. In high-motion joints, corticosteroids are often combined with HA [81].

Aseptic technique is vital for injection because of immunosuppressive effects of the drugs. In high-motion joints, steroids can lead to disruption of the chondro-osseous junction, with resultant cartilage detachment [81]. Corticosteroids are also implicated in the formation of steroid-induced arthropathies, metaplastic bone formation in soft tissues, and laminitis (particularly triamcinolone) [81]. Rates of such side effects are likely overestimated [80].

Corticosteroid effects seem to be dependent on drug and concentration. Although higher corticosteroid concentrations can decrease GAG synthesis, lower levels may be chondroprotective [82]. In explants taken from normal joints, low methylprednisolone acetate concentrations $(0.004 \mathrm{mg} / \mathrm{mL})$ had 
detrimental effects on synovial tissue, whereas moderate concentrations (1.0 and $0.1 \mathrm{mg} / \mathrm{mL}$ ) temporarily decreased GAG synthesis but also decreased proteoglycan release in response to stimulation $[82,83]$. Higher doses (corresponding to an $80-\mathrm{mg}$ intra-articular injection) led to severe but temporary depression of proteoglycan synthesis in cartilage explants [82]. When used in healthy joints or joints with osteochondral defects, methylprednisolone acetate at a dose of $100 \mathrm{mg}$ per site or greater resulted in cartilage damage or alteration, synovitis, and poor healing of defects, despite improvement in clinical signs in some studies $[80,84,85]$. Cartilage from younger animals seemed to be more sensitive to proteoglycan-depleting effects of the drug, and inflamed joints may not be as sensitive as healthy joints [86,87].

No significant positive or negative changes were detected after betamethasone injection using an osteochondral fragment exercise model [88]. A trend toward decreased staining and improved lameness was detected.

Triamcinolone (two doses of $12 \mathrm{mg}$ scheduled 2 weeks apart) resulted in improvement of lameness, lower synovial fluid protein, increased hyaluronan and GAG concentrations in synovial fluid, less synovial inflammation and fibrosis, and better histologic parameters for the articular cartilage [89]. Additionally, subchondral bone did not seem to be affected by similar intraarticular triamcinolone injections [90].

In general, until better determination of optimal dose and timing is obtained, repeated injections of intra-articular corticosteroids should be used with caution.

\section{Dimethyl sulfoxide}

Topical or intra-articular dimethyl sulfoxide (DMSO) has variable effects experimentally. After exposure to 5\% or greater DMSO, proteoglycan synthesis was reversibly inhibited in equine cartilage explants [91]. Detrimental effects $(10 \%$ solution) were detected in synovial explants [83]. When normal equine joints were lavaged with $10 \%$ and $30 \%$ DMSO, no difference was detected from lactated Ringer's solution in terms of joint inflammation [92]. Injection of $2 \mathrm{~mL}$ of $40 \%$ DMSO into equine joints with induced synovitis resulted in diminished white blood cell increases and a synovial inflammatory response and did not alter cartilage staining, hyaluronan concentration, or the lameness score [93]. Topical DMSO penetrated into equine joints with induced synovitis and decreased the neutrophilic response [94]. Analgesic effects of either topical or intra-articular DMSO in the horse have not been well investigated.

\section{Superoxide dismutase}

Initial studies on superoxide dismutase suggested it would be an effective intra-articular treatment for osteoarthritis in the horse [95,96]. Reactive oxygen species are implicated in cartilage aging, and inflammatory changes are involved in proteoglycan release [97]. Experimentally, catalase but not 
superoxide dismutase was able to prevent proteoglycan release from cartilage explants [97]. Oral bioavailability is also questionable [98]. Additionally, a recent analysis of six different compounds containing superoxide dismutase found content to be less than $5 \%$ of the label claim in all, perhaps as a result of lack of purification or destruction during the manufacturing or storage process [99].

\section{Antioxidants}

Supplementation with vitamin E, vitamin $\mathrm{C}$, or selenium has not been shown to be efficacious in the treatment of human osteoarthritis $[100,101]$. High doses of vitamin $\mathrm{C}$ were detrimental in a guinea pig model [102]. These compounds have not been well investigated in the horse.

\section{Sodium hyaluronate}

Hyaluronan is produced by the synovium and provides synovial membrane lubrication and joint fluid viscosity [103]. Poor hyaluronan levels or function may be evident with joint inflammation or osteoarthritis, particularly if radiographic changes are present [104]. Exogenous HA administration may help to restore joint function through improvement of synovial lubrication and through its anti-inflammatory and analgesic activities. HA is reported to modulate the inflammatory reaction by inhibiting chemotaxis, decreasing the stimulation and proliferation of lymphocytes, inhibiting neutrophil function, scavenging free radicals, and decreasing the production of $\mathrm{PGE}_{2}$ [103].

Equine in vitro and in vivo studies are difficult to evaluate because of mixed results. In vitro, $\mathrm{HA}$ decreased $\mathrm{PGE}_{2}$ production by equine synoviocytes at high concentrations (consistent with intra-articular administration) with the exception of $\mathrm{HA}$ derived from rooster comb, which increased $\mathrm{PGE}_{2}$ levels [105]. HA did not influence the molecular weight or rate of hyaluronan production, and higher concentrations of HA increased the production of collagenase from abnormal synovium [106].

Intra-articular treatment with HA has been described as useful in experimentally induced and naturally occurring lamenesses $[103,107]$. No improvement was detected in lameness grade or synovial parameters in a carpal synovitis model, however [108]. A combination of HA and methylprednisolone had better and longer lasting effects than methylprednisolone alone when used intra-articularly in racing Thoroughbreds and Standardbreds [109]. HA may also protect against the cartilage degradation potentially associated with steroid administration in the horse [110]. Overall, HA is believed to be most effective in mild to moderate cases of synovitis or capsulitis [103]. HA does not seem to have direct effects on the cartilage [103,111].

The standard dose of HA is approximately $20 \mathrm{mg}$ per site, with repeated doses possible in 2 to 3 weeks [81]. Repeated intra-articular administration 
may be associated with increased risk of flare reactions [103]. Higher molecular-weight products were associated with a longer duration of soundness in one study; however, most studies have found no significant difference in horses or other species [103].

Legend (Bayer Corporation, Shawnee Mission, KS) is an intravenous HA preparation that is gaining in use, particularly as a result of the perception that multiple joints may be effectively treated with one injection [81]. Recommended administration is $40 \mathrm{mg}$ once weekly for 3-4 weeks, followed by less frequent injections as needed for maintenance [81]. In the horse, intravenous HA administration persistently decreased lameness, improved synovial histopathology scores (less inflammation and vascularity), and decreased synovial protein and $\mathrm{PGE}_{2}$ levels after osteochondral fragmentation. No changes were seen in cartilage or in other synovial fluid parameters [112].

\section{Fatty acids}

Diets rich in $\omega-3$ (fish oil) and $\omega-6$ (evening primrose oil or olive oil) polyunsaturated fatty acids (PUFAs) may help to relieve inflammation by altering the eicosanoid spectrum. In people, long-term (6-12 months) intake of fish oils helps to reduce painful joints and minimize stiffness as well as decreasing the amount of NSAIDs required to control symptoms [113,114]. High doses are required to be effective in people $(2-5 \mathrm{~g} / \mathrm{d})$; it may be difficult to attain equivalent amounts in the equine diet [115]. This would equate to 18 to $24 \mathrm{~g} / \mathrm{d}$ for an adult horse. If more palatable linseed oil is used, a higher daily dose (estimated 90-120 g/d) would be required [116]. Linseed oil designed for furniture refinishing should not be used. To prevent oxidation, open containers should be used within 2 weeks. The compounds should be stored in light-resistant and air-tight containers. The oils can be frozen in plastic containers and thawed as needed. Supplemental antioxidants should be added before storage (final concentration of $1 \mathrm{~g} / \mathrm{kg}$ of $\alpha$-tocopherol or $\gamma$-tocopherol or $0.2 \mathrm{~g} / \mathrm{kg}$ of tertiary butylhydroquinone) [116]. Lipid-rich extracts from the New Zealand green-lipped mussel (Perna canaliculus) may be a more potent source of $\omega-3$ PUFAs [117].

\section{S-adenosyl-L-methionine}

S-adenosyl-L-methionine (SAMe) participates in a number of analgesic and anti-inflammatory reactions, giving it effects similar to those of NSAIDs [118]. Clinical studies in people have shown it to be effective for the treatment of osteoarthritis with minimal side effects $[119,120]$. In people, it is dosed initially IV at $400 \mathrm{mg} / \mathrm{d}$ for 5 days or orally at $600 \mathrm{mg} / \mathrm{d}$ for the first 2 weeks, followed by maintenance orally at 400 to $600 \mathrm{mg} / \mathrm{d}$. Response is noted at approximately 1 month after oral loading and 2 weeks after IV loading and can persist for 2 years after treatment ends [120,121]. Few 
veterinary studies have been performed; however, it was effective in altering the effects of chemically induced synovitis in dogs [118].

New anti-inflammatory agents

Agents that target matrix metalloproteinases, interleukin-1, or nitric oxide are being developed and are showing potential in experimental models [122-124]. Among these, the tetracycline group (including minocycline and doxycycline) can mitigate the side effects of arthritis, likely through cytokine-dependent actions of nitric oxide and metalloproteinases [125-127]. Oxaceprol ( $N$-acetyl-L-hydroxyproline) is an amino acid derivative that prevents leukocyte migration into joints; it seems to have equivalent effects on pain and mobility as diclofenac but was better tolerated $[128,129]$. Many botanical preparations are purported to decrease osteoarthritic pain through anti-inflammatory actions, including ginger, tumeric, Withania sominifera, Boswellia serrata, and avocado/soybean extract [130-132]. In most instances, more studies are required to confirm efficacy and determine side effects [122]. Enzymes like creatine and bromelain are unlikely to be of benefit in equine osteoarthritis [115].

\section{New delivery routes}

Local and topical anti-inflammatory agents seem to be effective in a variety of painful conditions in people [45]. These products may provide a means of achieving high local concentrations with minimal systemic levels and thus minimal adverse systemic effects.

Local infiltration of the NSAID bufexamac $(20 \mathrm{mg})$ was equivalent to 40 $\mathrm{mg}$ of triamcinolone in relieving clinical signs associated with shoulder periarthritis in people [133]. When horses with induced synovitis were injected with bufexamac (20-40 mg, two injections 1 week apart), the lameness index and stimulation of $\beta$-glucuronidase were decreased up to day 28 [134]. Up to six weekly injections of bufexamac $(20 \mathrm{or} 60 \mathrm{mg})$ in normal equine joints had no significant side effects compared with controls [135]. Contact sensitivity to the drug is common in people, however [136]. Work is being done to develop carriers that could extend the effective duration of treatment of these and other drugs, including chemotherapeutic agents [137].

Multiple formulations are being evaluated for transdermal drug delivery, either with penetrating carriers or with phoretic techniques [50]. Iontophoresis (using an electric potential gradient) and sonophoresis (using forced convection with ultrasound pressure waves) have been used to provide rapid noninvasive drug entry into tissues. These methods avoid injections, reduce risk of infection, and avoid first pass hepatic metabolism. They do require specialized equipment that is not yet readily available, however. Ketorolac, ketoprofen, diclofenac, and dexamethasone show promise for relieving painful symptoms of osteoarthritis [138-140]. 


\section{Chondroprotection}

The primary proteoglycans in the horse are chondroitin sulfate and keratan sulfate. Hyaline cartilage in older horses contains less chondroitin sulfate and more keratan and dermatan sulfates [54]. These sulfates form weaker bonds with collagen, leading to decreased tensile strength and increased susceptibility to injury. Much work has been done in recent years to evaluate agents that are designed to provide the matrix components that might otherwise be in short supply in inflamed or arthritic joints. These are otherwise known as slow-acting drugs of osteoarthritis.

\section{Polysulfated glycosaminoglycan}

Polysulfated glycosaminoglycan (PSGAG; Adequan; Luitpold Pharmaceuticals, Shirley, NY) is a semisynthetic polysulfated chondroitin sulfate manufactured from bovine lung and trachea. Recommended protocols include $250 \mathrm{mg}$ administered intra-articularly once weekly for 3 to 5 weeks or $500 \mathrm{mg}$ administered IM every 3 to 7 days for a minimum of 4 to 5 weeks, followed by maintenance treatment of $500 \mathrm{mg}$ administered IM once or twice monthly [81,141]. Intra-articular treatment is associated with an increased risk of joint sepsis and nonseptic inflammatory reactions [141]. After IM injection of $500 \mathrm{mg}$ of PSGAG, therapeutic levels $(0.1-1.0 \mu \mathrm{g} / \mathrm{mL})$ were present in synovial fluid within 2 hours and within cartilage within 8 hours; levels persisted for 96 hours [142].

PSGAG seems to have the potential for anti-inflammatory activity and direct stimulation of cartilage neosynthesis. Various studies have shown that PSGAG can stimulate hyaluronan, collagen, and GAG synthesis as well as chondrocyte replication; however, effects seem to be concentration and joint dependent, with some effects only being obtained with intra-articular injection [141,143].

In the horse and other species, PSGAG has also been found to inhibit lysosomal enzymes, reduce the synthesis of prostaglandins and interleukins, inhibit complement activity, and inhibit the release of free radicals [105,141]. Osteoarthritic cartilage also seems to be more sensitive to the effects of PSGAG than normal cartilage in vitro [144].

In an osteoarthritic model, PSGAG was found to be protective against the chondrolytic and cartilage-destroying effects of MIA when given intraarticularly but not IM [145]. Treated joints had less joint circumference enlargement, less articular cartilage fibrillation and erosion, and less chondrocyte death. In ponies with osteochondral defects, intra-articular PSGAG seemed to protect against loss of proteoglycan from articular cartilage, leading to less keratan sulfate in the synovial fluid [146]. PSGAG did not alter defect appearance, total collagen content, uronic acid content, or proportions of type I and II collagen in equine osteochondral defects, however, nor did it prevent corticosteroid-induced decreases in articular cartilage levels of 
proteoglycan and fibronectin in ponies [111,144,145]. Additionally, kissing lesions opposite osteochondral lesions were unchanged grossly but had increased total fibronectin content after treatment with intra-articular PSGAG [111,147]. Because fibronectin is increased in osteoarthritic cartilage, this raises concerns about the potential for PSGAG-induced alteration in chondrocyte function and matrix disruption [148]. When ponies with osteochondral defects were exercised, intra-articular PSGAG treatment resulted in increased range of motion, less capsulitis and joint effusion, and decreased radiographic evidence of osteoarthritis than in nontreated exercised ponies [149]. There seemed to be increased release of proteoglycans from cartilage in treated compared with nontreated ponies and less type II than type I collagen in defects [146,149]. The latter may be more of a concern in acute rather than chronic cartilage defects [147,148].

In 15 horses diagnosed with navicular disease (with $<1$ year duration), $500 \mathrm{mg}$ of PSGAG given IM for seven treatments every 4 days was found to improve lameness and response to flexion [150]. Subjectively, PSGAG was found to be moderately effective in the treatment of osteoarthritis and lameness, especially in racehorses $[107,151]$.

Pentosan polysulfate is derived from beech hemicellulose and has a chemical structure similar to that of PSGAG. Pentosan $(2 \mathrm{mg} / \mathrm{kg}$ IM twice weekly) did not alter steroid-induced proteoglycan depletion in carpal joints of ponies [86]. When given to racing Thoroughbreds with chronic osteoarthritis (2-3 mg/kg IM once weekly for 4 weeks, then as required), pentosan treatment improved but did not eliminate clinical signs of joint disease. The most striking change was in the reduced lameness 24 hours after racing [152].

PSGAG should be of minimal risk when given IM. If given intra-articularly, concurrent antibiotic (125 mg of amikacin) injection is recommended [81]. PSGAG produces transient dose-dependent effects on coagulation times in horses; however, no clinical correlations have been detected [148].

\section{Glucosamine and chondroitin}

Glucosamine is an important intermediate for numerous compounds, including GAGs [141]. When given orally, salts of glucosamine (hydrochloride or sulfate) are well absorbed, diffuse into all body tissues, and concentrate in articular cartilage [141]. Almost 50\% more of the sulfate salt is required to provide an equal amount of bioactive glucosamine as the hydrochloride salt, however [153]. $N$-acetylglucosamine was found to be less efficacious in cell culture than other glucosamine products [154]. In other species, glucosamine has been shown to enhance chondrocyte synthesis of GAGs and collagen, minimize synovitis, and provide symptomatic relief from osteoarthritis [118,153]. Nevertheless, $100 \mu \mathrm{g} / \mathrm{mL}$ of glucosamine decreased viability of canine chondrocytes, decreased GAG production, and did not alter $\mathrm{PGE}_{2}$ levels [155]. The remainder of the veterinary studies have evaluated a combination of glucosamine hydrochloride and chondroitin sulfate. 
Chondroitin sulfate is the most abundant GAG in cartilage [141]. Chondroitin-6-sulfate is primarily derived from shark cartilage, whereas chondroitin-4-sulfate is most abundant in mammalian cartilage, particularly that of young animals [156]. Decreases in chondroitin sulfate levels have been associated with the formation of occlusive microthrombi in the microvasculature, and age-related decreases could be associated with synovial or bone degeneration [156]. Recent studies have shown oral absorption of chondroitin sulfate in rats, dogs, and human beings [157]. In other species, chondroitin sulfate has been shown to have anti-inflammatory properties, is able to decrease interleukin-1 production, blocks complement activation, and inhibits metalloproteinase activity [158]. It seems to be effective in decreasing pain and protecting cartilage in people [158]. Injectable (IM) and oral chondroitin sulfate both decreased joint effusion, synovial fluid protein levels, and response to flexion in an experimental model of equine synovitis [159].

Meta-analysis of research in people showed that all but one of the published clinical trials for glucosamine and chondroitin were positive for controlling symptoms of osteoarthritis [153]. Major deficiencies were detected in descriptions of randomization, masking, and completion rates, however. A publication bias (exaggerated estimates of benefit) was also present.

The most tested of the veterinary products is a patented combination of glucosamine hydrochloride, chondroitin sulfate, and manganese ascorbate (Cosequin; Nutramax Laboratories, Edgewood, MD). Glucosamine and chondroitin sulfate have been suggested to work synergistically to increase cartilage metabolism and inhibit cartilage degradation [156]. Manganese ascorbate is an essential cofactor in the synthesis of GAGs and stimulates efficient GAG production when added to glucosamine [156]. It may also function as an antioxidant [156]. The salt form of manganese is well absorbed after oral administration, and no toxic effects have been reported [156]. Cosequin is dosed at $22 \mathrm{mg} / \mathrm{kg}$ of glucosamine hydrochloride plus $8.8 \mathrm{mg} / \mathrm{kg}$ of low-molecular-weight chondroitin sulfate. Cosequin has a shelf life of approximately 2 years when stored tightly closed at room temperature in a dry location away from direct sunlight.

Two trials in horses suggest that Cosequin is useful for the treatment of equine osteoarthritis ( 25 horses) and navicular syndrome ( 8 horses), with improvement observed in lameness scores, response to flexion, and other tested parameters $[160,161]$. In a third study, no benefit was observed in a 26-day trial evaluating Cosequin's effects on induced synovitis, including lameness score, range of motion, joint circumference, and synovial protein levels [162]. Most reports suggest that it takes 4 to 6 weeks for clinical changes to be detectable $[158,163]$.

Cosequin was found to alter hemostatic and hematologic values in other species, but all values stayed within normal ranges and none were considered to be of clinical significance [164]. Stool softening and gas were detected in less than $2 \%$ of dogs tested [163]. Six adult mares given five times the 
minimum dose for 35 days did not show clinically significant alterations in laboratory values or synovial fluid protein [165]. Nevertheless, because of the similarity of GAG to heparin, care should be taken when it is used with other platelet inhibitors, such as phenylbutazone, in animals that may be predisposed to bleeding problems [158], but no clinical problems have been reported with the combination [72]. Adverse effects have been reported with mixtures containing glucosamine, chondroitin sulfate, and herbal extracts [158].

These slow-acting drugs of osteoarthritis should be most effective in early-stage osteoarthritis, and time is required to obtain full benefit. In people, marked divergence from placebo was noted at 2 years [166]. Difficulties exist in determining clinical effect because of the variable nature of osteoarthritis: clinical signs vary over time and with exercise and shoeing changes [56].

Use of either PSGAG or Cosequin is not inexpensive [81]. Several similar compounds have come on the market in competition. Most feed additives contain glucosamine alone or in combination with chondroitin sulfate. No studies have been done comparing the combination product with the individual components. With all oral joint protectants, care should be taken when selecting a product. Most of these agents are classified as nutraceuticals and are not regulated by the US Food and Drug Administration. As such, there is no requirement to specify efficacy or safety of a compound even though claims can be made on structure or function [158]. Many veterinary compounds are not fully tested, and there is no reporting system for the side effects of these compounds [167]. With such lack of information, it is hard to select among the hundreds of compounds. Many compounds do not meet label claims, making confidence in the manufacturer important [167]. Oral bioavailability information is also critical. The veterinarian should request information on the quality (purity), contents, consistency, and storage of all products before making a recommendation. Guaranteed analysis reports would be ideal [115]. Lower purity compounds may have safety risks, such as protein hypersensitivity caused by the shellish used to produce glucosamine [158]. In unpure products, chondroitin sulfate may bind to aggrecan and be poorly available [115]. Shark cartilage is a common source of chondroitin sulfate but requires extensive processing [153]. Sea algae and gelatin are proposed sources of raw GAG, but true GAGs can only be obtained from animal sources (and some bacteria) [115]. There is no proof that either of these sources aids in the treatment of osteoarthritis. There are now reference texts [168] and web sites (www.drtheo.com, www.quackwatch. com) attempting to help with the decision.

\section{Diacerein}

Recent work suggests that a novel NSAID, diacerein, and its active metabolite rhein may act as disease-modifying agents of osteoarthritis 
because of structural benefits of the drug. Properties include modulation of inflammation and mediation of cartilage and subchondral bone responses in osteoarthritis [169-171]. Clinical use found that diacerein was able to modify progressive joint space narrowing in patients with hip osteoarthritis and was well tolerated, even in older patients and in those with renal or hepatic disease $[172,173]$.

\section{Cartilage repair or replacement: arthroplasty}

The repair response of cartilage is inadequate for equine weight bearing, even for small defects. Extensive efforts have been directed to surgical enhancement of the healing of full-thickness defects. Many techniques improve the quality and attachment of fibrous tissue, but none have resulted in persistent hyaline cartilage [174-176]. Mosaic arthroplasty and other forms of fresh osteochondral autografts show promise, but difficulties arise in donor site selection in terms of cartilage thickness and physical properties [175]. Even more promising areas include chondrocyte transplantation, growth factor application, and gene therapy (eg, interleukin-1 receptor antagonist protein) $[176,177]$.

\section{Performance animals}

Many horses continue to perform despite osteoarthritis. The added expense of joint protectants is often recommended to maximize performance and longevity. Combination therapy using agents from different categories may provide the best results with minimal toxicity and may be mandatory if drug restrictions are a concern. Additional attention to the rest of the horse is also warranted. When in pain, animals may not move appropriately or may try to protect one area at the expense of another. Horses with hind limb pain often have back and croup muscle soreness, whereas those with forelimb problems often have neck, shoulder, and bicipital muscle pain. Massage, heat, and acupuncture may help with sore muscles, as can stretching activities and prolonged warm-up periods [32,178]. Analgesics should be used as needed to minimize muscle soreness. Lunging, tight ring work, and repetitious exercises should be avoided. For experienced horses and riders, keeping the animal fit and relaxed may be more important than practicing drills outside of the show ring.

\section{Breeding animals}

In animals being used only for breeding, analgesia is the primary goal. Chondroprotective agents may not be cost-effective. Additionally, most drugs have not been tested in pregnant animals, and many can have potential adverse effects on the fetus and neonate. 
Teratogenic effects are most common in the first trimester. Chemotherapeutic drugs should be avoided in the first trimester and may have effects on stallion performance [179]. Tetracyclines should not be given during pregnancy because of bone-related effects [180]. Phenylbutazone does cross the placenta, and the drug half-life is longer in neonatal foals than in adults [181]. Young foals may be more sensitive to the toxic effects of phenylbutazone, and foals have been born with gastric ulceration and renal failure apparently acquired in utero $[182,183]$. Conversely, only low amounts of phenylbutazone are detected in milk from treated mares [183]. In early gestation, NSAIDs have been reported to cause fetal malformations in other species [184]. In late gestation, use of NSAIDS may lead to premature ductus arteriosus closure and premature labor [184].

\section{Summary}

Many compounds are being investigated for the control of symptoms of osteoarthritis in people and animals. Ideally, treatment should include analgesia, inflammation control, and chondroprotection. With further progress in this area, combination therapies tailored to the needs of the individual animal should enable us to maximize efficacy and minimize side effects. Only a few of the newer therapies and pharmaceutic agents have been investigated in the horse, however. With more rigorous investigation, they may be determined to be ineffective or unsafe. Meanwhile, as much information should be gathered from manufacturers as possible so as to ensure that appropriate recommendations are made.

\section{References}

[1] Kyles AE, Ruslander D. Chronic pain: osteoarthritis and cancer. Semin Vet Med Surg 1997;12:122-32.

[2] Muir WW, Woolf CJ. Mechanisms of pain and their therapeutic implications. JAVMA 2001;219:1346-56.

[3] Todhunter RJ, Lust G. Pathophysiology of synovitis: clinical signs and examination in horses. Compend Contin Educ Pract Vet 1990;12:980-91.

[4] Caron JP. Neurogenic factors in joint pain and disease pathogenesis. In: McIlwraith CW, Trotter GW, editors. Joint disease in the horse. Philadelphia: WB Saunders; 1996. p. 71-80.

[5] McIlwraith CW, Vachon A. Review of pathogenesis and treatment of degenerative joint disease. Equine Vet J Suppl 1988;6:3-11.

[6] McIlwraith CW, Bramlage LR. Surgical treatment of joint injury. In: McIlwraith CW, Trotter GW, editors. Joint disease in the horse. Philadelphia: WB Saunders; 1996. p. 292-317.

[7] Theoret CL, Barber SM, Moyana TN, Townsend HGG, Archer J. Repair and function of synovium after total arthroscopic synovectomy of the equine antebrachiocarpal joint [abstract]. Vet Surg 1994;23:418.

[8] Palmer JL, Bertone AL, Malemud CJ, Mansour J. Changes in third carpal bone articular cartilage after synovectomy in normal and inflamed joints. Vet Surg 1998;27:321-30. 
[9] Kampen WU, Brenner W, Kroeger S, Sawula JA, Bohuslavizki KH, Henze E. Long-term results of radiation synovectomy: a clinical follow-up study. Nucl Med Commun 2001;22: $239-46$.

[10] Rodriguez-Merchan EC, Goddard NJ. The technique of synoviorthosis. Haemophilia 2001;7(Suppl 2):11-5.

[11] Yarbrough TB, Lee MR, Hornof WJ, Koblik PD, Brodack J, Troup C, et al. Samarium 153-labeled hydroxyapatite microspheres for radiation synovectomy in the horse: a study of the biokinetics, dosimetry, clinical, and morphologic response in normal metacarpophalangeal and metatarsophalangeal joints. Vet Surg 2000;29:191-9.

[12] Auer JA. Arthrodesis techniques. In: Auer JA, Stick JA, editors. Equine surgery. 2nd edition. Philadelphia: WB Saunders; 1999. p. 696-704.

[13] Caron JP, Fretz PB, Bailey JV, Barber SM. Proximal interphalangeal arthrodesis in the horse: a retrospective study and a modified screw technique. Vet Surg 1990;19: 196-202.

[14] Schaer T, Bramlage L, Embertson R, Hance S. Proximal interphalangeal arthrodesis in 22 horses [abstract]. Vet Surg 1998;27:516.

[15] Adams OR. Surgical arthrodesis for the treatment of bone spavin. JAVMA 1970;157: $1480-5$.

[16] Trotter GW. Management of bone spavin. In: Proceedings of the 18th Annual Veterinary Surgical Forum (Large Animal), Chicago. Bethesda (MD): American College of Veterinary Surgeons; 1990. p. 283-4.

[17] Wyn-Jones G, May SA. Surgical arthrodesis for the treatment of osteoarthrosis of the proximal intertarsal, distal intertarsal and tarsometatarsal joints in 30 horses: a comparison of four different techniques. Equine Vet J 1986;18:59-64.

[18] Archer RM, Schneider RK, Lindsay WA, Wilson JW. Arthrodesis of the equine distal tarsal joints by perforated stainless steel cylinders. Equine Vet J Suppl 1988;6:125-30.

[19] Sonnichsen HV, Svalastoga E. Surgical treatment of bone spavin in the horse. Equine Pract 1985;7:6-9.

[20] Bohanon TC. Tarsal arthrodesis. In: White NA, Moore JN, editors. Current techniques in equine surgery and lameness. 2nd edition. Philadelphia: WB Saunders; 1998. p. 433-9.

[21] Arighi M, Miller CR, Pennock PW. Arthrodesis of the scapulohumeral joint in a miniature horse. JAVMA 1987;191:713-4.

[22] Felson DT, Lawrence RC, Hochberg MC, McAlinson T, Dieppe PA, Minor MA, et al. Osteoarthritis: new insights; part 2. Treatment approaches. Ann Intern Med 2000;133: 726-37.

[23] Hurtig MB, Fretz PB, Doige CE, Schnurr D. Effects of lesion size and location on equine articular cartilage repair. Can J Vet Res 1988;52:137-46.

[24] Ramey DW. Horseshoeing and its effects on joints. In: Concise guide to arthritis in the horse. NewYork: Howell Book House; 1998. p. 99-102.

[25] Xie H. Treating equine lameness with acupuncture. Compend Contin Educ Pract Vet 2001;23:838-41.

[26] Ezzo J, Hadhazy V, Birch S, Lao L, Kaplan G, Hochberg M, et al. Acupuncture for osteoarthritis of the knee: a systematic review. Arthritis Rheum 2001;44:819-25.

[27] Berman BM, Singh BB, Lao L, Langenberg P, Li H, Hadhazy V, et al. A randomized trial of acupuncture as an adjunctive therapy in osteoarthritis of the knee. Rheumatology 1999;38:346-54.

[28] Puett DW, Griffin MR. Published trials of nonmedicinal and noninvasive therapies for hip and knee osteoarthritis. Ann Intern Med 1994;121:133-40.

[29] Ramey DW. Magnetic and electromagnetic therapy in horses. Compend Contin Educ Pract Vet 1999;21:553-60.

[30] Jacobson JI, Gorman R, Yamanashi WS, Saxena BB, Clayton L. Low-amplitude, extremely low frequency magnetic fields for the treatment of osteoarthritic knees: a double-blind clinical study. Altern Ther Health Med 2001;7:54-64. 
[31] Weinberger A, Nyska A, Giler S. Treatment of experimental inflammatory synovitis with continuous magnetic field. Isr J Med Sci 1996;32:1197-201.

[32] Millis DL, Levine D. The role of exercise and physical modalities in the treatment of osteoarthritis. Vet Clin North Am Small Anim Pract 1997;27:913-30.

[33] Carroll D, Moore RA, McQuay HJ, Fairman F, Tramer M, Leijon G. Transcutaneous electrical nerve stimulation (TENS) for chronic pain. Cochrane Database Syst Rev 2001;3:CD003222.

[34] Osiri M, Welch V, Brosseau L, Shea B, McGowan J, Tugwell P, et al. Transcutaneous electrical nerve stimulation for knee osteoarthritis. Cochrane Database Syst Rev 2000;4: CD002823.

[35] Steiss JE. Physical therapy modalities: therapeutic ultrasound and phonophoresis. Compend Contin Educ Pract Vet 2000;22:690-3.

[36] Brosseau L, Welch V, Wells G, Tugwell P, de Bie R, Gam A, et al. Low level laser therapy for osteoarthritis and rheumatoid arthritis: a meta-analysis. J Rheumatol 2000;27: 1961-9.

[37] Zhang WY, Li Wan Po A. The effectiveness of topically applied capsaicin. A metaanalysis. Eur J Clin Pharmacol 1994;46:517-22.

[38] McCleane G. The analgesic efficacy of topical capsaicin is enhanced by glyceryl trinitrate in painful osteoarthritis: a randomized, double blind, placebo controlled study. Eur J Pain 2000;4:355-60.

[39] Weinberger T, Nolting B. Focused extracorporeal shockwave therapy in sport horses [abstract 35]. In: Proceedings of the Fourth Congress of the International Society for Musculoskeletal Shockwave Therapy, Berlin. Vienna: International Society for Musculoskeletal Shockwave Therapy; 2001.

[40] McClure S, Van Sickle D, McCarroll D. Equine applications of extracorporeal shockwave therapy [abstract 34]. In: Proceedings of the Fourth Congress of the International Society for Musculoskeletal Shockwave Therapy, Berlin. Vienna: International Society for Musculoskeletal Shockwave Therapy; 2001.

[41] Boddeker R, Schafer H, Haake M. Extracorporeal shockwave therapy (ESWT) in the treatment of plantar fasciitis - a biometrical review. Clin Rheumatol 2001;20:324-30.

[42] Natalini CC, Robinson EP. Evaluation of the analgesic effects of epidurally administered morphine, alfentanil, butorphanol, tramadol and U0488H in horses. Am J Vet Res 2000; 61:1579-86.

[43] Liu SS, Hodgson PS, Carpenter RI, Fricke Jr JR. ADL 8-2698, a trans-3,4-dimethyl-4-(3hydroxyphenyl) piperidine, prevents gastrointestinal effects of intravenous morphine without affecting analgesia. Clin Pharmacol Ther 2001;69:66-71.

[44] Curatolo M, Bogduk N. Pharmacologic pain treatment of musculoskeletal disorders: current perspectives and future prospects. Clin J Pain 2001;17:25-32.

[45] Lamont LA, Tranquilli WJ, Mathews KA. Adjunctive analgesic therapy. Vet Clin North Am Small Anim Pract 2000;30:805-13.

[46] Gok S, Onal A, Cinar MG, Evinc A. The antinociceptive effect of leukotriene $\mathrm{D}_{4}$ receptor antagonist, MK-571, in mice: possible involvement of opioidergic mechanism. Eur $\mathbf{J}$ Pharmacol 1999;386:195-200.

[47] Chan WH, Lin CJ, Sun WZ, Tsai SP, Tsai SK, Hsieh CY. Comparison of subcutaneous hydromorphone with intramuscular meperidine for immediate postoperative analgesia. Kaohsiung J Med Sci 1999;15:419-27.

[48] Lesser GJ, Grossman SA, Leong KW, Lo H, Eller S. In vitro and in vivo studies of subcutaneous hydromorphone implants designed for the treatment of cancer pain. Pain 1996;65:265-72.

[49] Matthews NS, Peck KE, Mealy KL. Transdermal fentanyl: absorption and plasma levels in horses. In: Proceedings of the Sixth International Congress of Veterinary Anesthesiology, Thessaloniki, Greece. Knoxville (TN): American College of Veterinary Anesthesiologists; 1997. p. 116. 
[50] Barry BW. Novel mechanisms and devices to enable successful transdermal drug delivery. Eur J Pharm Sci 2001;14:101-14.

[51] Langerman L, Grant GJ, Zakowski M, Golomb E, Ramanathan S, Turndorf H. Prolongation of epidural anesthesia using a lipid drug carrier with procaine, lidocaine, and tetracaine. Anesth Analg 1992;75:900-5.

[52] Masters DB, Berde CB, Dutta S, Turek T, Langer R. Sustained local anesthetic release from bioerodible polymer matrices: a potential method for prolonged regional anesthesia. Pharm Res 1993;10:1527-32.

[53] Palmer JL, Bertone AL. Joint structure, biochemistry and biochemical disequilibrium in synovitis and equine joint disease. Equine Vet J 1994;26:263-77.

[54] Todhunter RJ. Anatomy and physiology of synovial joints. In: McIlwraith CW, Trotter GW, editors. Joint disease in the horse. Philadelphia: WB Saunders; 1996. p. 1-28.

[55] MacDonald MH, Benton HP. Cellular responses and receptor mechanisms in joint disease: a bacterial lipopolysaccharide-induced model of articular damage. In: McIlwraith CW, Trotter GW, editors. Joint disease in the horse. Philadelphia: WB Saunders; 1996. p. $447-67$.

[56] Kawcak CE. New thinking about chondroprotection. Compend Contin Educ Pract Vet 2000;22(Suppl 5A):14-6.

[57] Collins LG, Tyler DE. Phenylbutazone toxicosis in the horse: a clinical study. JAVMA 1984;184:699-703.

[58] Owens JG, Kamerling SG, Stanton SR, Keowen ML, Prescott-Matthews JS. Effects of pretreatment with ketoprofen and phenylbutazone on experimentally induced synovitis in horses. Am J Vet Res 1996;57:866-74.

[59] Owens JG, Kamerling SG, Stanton SR, Keowen ML. Effects of ketoprofen and phenylbutazone on chronic hoof pain and lameness in the horse. Equine Vet J 1995; 27:296-300.

[60] Houdeshell JW, Hennessey PW. A new non-steroidal, anti-inflammatory analgesic for horses. J Equine Med Surg 1977;1:57-63.

[61] MacAllister CG, Morgan SJ, Borne AT, Pollet RA. Comparison of adverse effects of phenylbutazone, flunixin meglumine, and ketoprofen in horses. JAVMA 1993;202: $71-7$.

[62] Gregoricka MJ, Sutherland SF, Dedrickson BJ, Busch KR. Assessment of the intramuscular administration of ketoprofen. Equine Pract 1990;12:15-22.

[63] Breuhaus BA, DeGraves FJ, Honore EK, Papich MG. Pharmacokinetics of ibuprofen after intravenous and oral administration and assessment of safety of administration to healthy foals. Am J Vet Res 1999;60:1066-73.

[64] Hamm D, Turchi P, Johnson JC, Lockwood PW, Thompson KC, Katz T. Determination of an effective dose of eltenac and its comparison with that of flunixin meglumine in horses after experimentally induced carpitis. Am J Vet Res 1997;58:298-302.

[65] Prugner W, Huber R, Luhmann R. Eltenac, a new anti-inflammatory and analgesic drug for horses: clinical aspects. J Vet Pharmacol Ther 1991;14:193-9.

[66] Lees P, Higgins AJ. Clinical pharmacology and therapeutic uses of non-steroidal antiinflammatory drugs in the horse. Equine Vet J 1985;17:83-96.

[67] Jaraiz MV, Rodriguez C, San Andres MD, Gonzalez F, San Andres MI. Disposition and tolerance of suxibuzone in horses. Equine Vet J 1999;31:411-6.

[68] Jones EW, Hamm D. Comparative efficacy of phenylbutazone and naproxen in induced equine myositis. J Equine Med Surg 1978;2:341-7.

[69] McKellar QA, Bogan JA, von Fellenberg RL, Ludwig B, Cawley GD. Pharmacokinetic, biochemical and tolerance studies on carprofen in the horse. Equine Vet J 1991;23: $280-4$.

[70] Soma LR, Uboh CE, Rudy JA, Smith MS. Disposition and excretion of 6-methoxy-2naphthylacetic acid, the active metabolite of nabumetone in horses. Am J Vet Res 1996;57:517-21. 
[71] Day RO, McLachlan AJ, Graham GG, Williams KM. Pharmacokinetics of nonsteroidal anti-inflammatory drugs in synovial fluid. Clin Pharmacokinet 1999;36:191-210.

[72] Papich MG. Pharmacologic considerations for opiate analgesic and nonsteroidal antiinflammatory drugs. Vet Clin North Am Small Anim Pract 2000;30:815-37.

[73] Rose RJ, Kohnke JR, Baggot JD. Bioavailability of phenylbutazone preparations in the horse. Equine Vet J 1982;14:234-7.

[74] Vandenbossche GMR, Bouckaert S, De Muynck C, Mommens G, Van Zeveren A, Remon J-P. Bioavailability of two ibuprofen oral paste formulations in fed or nonfed ponies. Am J Vet Res 1992;53:528-31.

[75] Semrad SD, Sams RA, Harris ON, Ashcroft SM. Effects of concurrent administration of phenylbutazone and flunixin meglumine on pharmacokinetic variables and in vitro generation of thromboxane $B_{2}$ in mares. Am J Vet Res 1993;54:1901-5.

[76] Lees P, Maitho TE, Taylor JB. Pharmacokinetics of phenylbutazone in two age groups of ponies: a preliminary study. Vet Rec 1985;116:229-32.

[77] Landoni MF, Foot R, Frean S, Lees P. Effects of flunixin, tolfenamic acid, R(-) and S(+) ketoprofen on the response of equine synoviocytes to lipopolysaccharide stimulation. Equine Vet J 1996;28:468-75.

[78] Beluche LA, Bertone AL, Anderson DE, Rohde C. Effects of oral administration of phenylbutazone to horses on in vitro articular cartilage metabolism. Am J Vet Res 2001;62:1916-21.

[79] May SA, Lees P. Nonsteroidal anti-inflammatory drugs. In: McIlwraith CW, Trotter GW, editors. Joint disease in the horse. Philadelphia: WB Saunders; 1996. p. 223-37.

[80] Trotter GW. Intra-articular corticosteroids. In: McIlwraith CW, Trotter GW, editors. Joint disease in the horse. Philadelphia: WB Saunders; 1996. p. 237-56.

[81] Black JB. Management of equine joint disease and lameness. Compend Contin Educ Pract Vet 2000;22(Suppl 5A):10-3.

[82] Murphy DJ, Todhunter RJ, Fubini SL, Vernier-Singer M, Straubinger RK, Lust G. The effects of methylprednisolone on normal and monocyte-conditioned medium-treated articular cartilage from dogs and horses. Vet Surg 2000;29:546-57.

[83] Moses VS, Hardy J, Bertone AL, Weisbrode SE. Effects of anti-inflammatory drugs on lipopolysaccharide-challenged and -unchallenged equine synovial explants. Am J Vet Res 2001;62:54-60.

[84] Carter BG, Bertone AL, Weisbrode SE, Bailey MQ, Andrews JM, Palmer JL. Influence of methylprednisolone acetate on osteochondral healing in exercised tarsocrural joints of horses. Am J Vet Res 1996;57:914-22.

[85] Frisbie DD, Kawcak CE, Baxter GM, Trotter GW, Powers BE, Lassen ED, et al. Effects of $6 \alpha$-methylprednisolone acetate on an equine osteochondral fragment exercise model. Am J Vet Res 1998;59:1619-28.

[86] Fubini SL, Boatwright CE, Todhunter RJ, Lust G. Effect of intramuscularly administered polysulfated glycosaminoglycan on articular cartilage from equine joints injected with methylprednisolone acetate. Am J Vet Res 1993;54:1359-65.

[87] Todhunter RJ, Fubini SL, Vernier-Singer M, Wootton JAM, Lust G, Freeman KP, et al. Acute synovitis and intra-articular methylprednisolone acetate in ponies. Osteoarthritis Cartilage 1998;6:94-105.

[88] Foland JW, McIlwraith CW, Trotter GW, Powers BE, Lamar CH. Effect of betamethasone and exercise on equine carpal joints with osteochondral fragments. Vet Surg 1994;23:369-76.

[89] Frisbie DD, Kawcak CE, Trotter CW, Powers BE, Walton RM, McIlwraith CW. Effects of triamcinolone acetonide on an in vivo equine osteochondral fragment exercise model. Equine Vet J 1997;29:349-59.

[90] Kawcak CK, Norrdin RW, Trotter GW. Effects of osteochondral fragmentation and intra-articular triamcinolone acetonide treatment on subchondral bone in the equine carpus. Equine Vet J 1998;30:66-71. 
[91] Smith CL, Macdonald MH, Tesch AM, Willits NH. In vitro evaluation of the effect of dimethyl sulfoxide on equine articular cartilage matrix metabolism. Vet Surg 2000;29:347-57.

[92] Adair HS, Goble DO, Vanhooser S, Blackford JT, Rohrbach BW. Evaluation of use of dimethyl sulfoxide for intra-articular lavage in clinically normal horses. Am J Vet Res 1991;52:333-6.

[93] Welch RD, Watkins JP, DeBowes RM, Leipold HW. Effect of intra-articular administration of dimethyl sulfoxide on chemically induced synovitis in immature horses. Am J Vet Res 1991;52:934-9.

[94] Smith G, Bertone AL, Kaeding C, Simmons EJ, Apostoles S. Anti-inflammatory effects of topically applied dimethyl sulfoxide gel on endotoxin-induced synovitis in horses. Am J Vet Res 1998;59:1149-52.

[95] Ahlengard S, Tufvesson G, Pettersson H, Andersson T. Treatment of traumatic arthritis in the horse with intra-articular orgotein (Palosein). Equine Vet J 1978;10:122-4.

[96] McIlwain H, Silverfield JC, Cheatum DE, Poiley J, Taborn J, Ignaczak T, et al. Intraarticular orgotein in osteoarthritis of the knee: a placebo-controlled efficacy, safety and dosage comparison. Am J Med 1989;87:295-300.

[97] Tiku ML, Gupta S, Deshmukh DR. Aggrecan degradation in chondrocytes is mediated by reactive oxygen species and protected by antioxidants. Free Radic Res 1999;30:395-405.

[98] Giri SN, Misra HP. Fate of superoxide dismutase in mice following oral administration. Med Biol 1984;62:285-9.

[99] Beale BS. Evaluation of active enzyme activity in six oral superoxide dismutase products. In: Proceedings of the 25th Annual Conference of the Veterinary Orthopedic Society, Snowmass. Newmarket (NH): Veterinary Orthopedic Society; 1998. p. 65.

[100] Brand C, Snaddon J, Bailey M, Cicuttini F. Vitamin E is ineffective for symptomatic relief of knee osteoarthritis: a six month double blind, randomised, placebo controlled study. Ann Rheum Dis 2001;60:946-9.

[101] Hill J, Bird HA. Failure of selenium-ACE to improve osteoarthritis. Br J Rheumatol 1990;29:211-3.

[102] Schwartz ER, Leveille C, Oh WH. Experimentally-induced osteoarthritis in guinea pigs: effect of surgical procedure and dietary intake of vitamin C. Lab Anim Sci 1981;31: 683-7.

[103] Howard RD, McIlwraith CW. Hyaluronan and its use in the treatment of equine joint disease. In: McIlwraith CW, Trotter GW, editors. Joint disease in the horse. Philadelphia: WB Saunders; 1996. p. 257-69.

[104] Tulamo RM, Heiskanen T, Salonen M. Concentration and molecular weight distribution of hyaluronate in synovial fluid from clinically normal horses and horses with diseased joints. Am J Vet Res 1994;55:710-5.

[105] Frean SP, Lees P. Effects of polysulfated glycosaminoglycan and hyaluronan on prostaglandin $E_{2}$ production by cultured equine synoviocytes. Am J Vet Res 2000;61: 499-505.

[106] Lynch TM, Caron JP, Arnoczky SP, Lloyd JW, Stick JA, Render JA. Influence of exogenous hyaluronan on synthesis of hyaluronan and collagenase by equine synoviocytes. Am J Vet Res 1998;59:888-92.

[107] Gaustad G, Larsen S. Comparison of polysulphated glycosaminoglycan and sodium hyaluronate with placebo in treatment of traumatic arthritis in horses. Equine Vet J 1995; 27:356-62.

[108] Peloso JG, Stick JA, Caron JP, Peloso PM, Soutas-Little RW. Effects of hylan on amphotericin-induced carpal lameness in equids. Am J Vet Res 1993;54:1527-34.

[109] Rydell NW, Butler J, Balazs EA. Hyaluronic acid in synovial fluid. VI. Effect of intraarticular injection of hyaluronic acid on the clinical symptoms of arthritis in track horses. Acta Vet Scand 1970;11:139-55.

[110] Roneus B, Lindblad A, Lindholm A, Jones B. Effects of intraarticular corticosteroid and sodium hyaluronate injections on synovial fluid production and synovial fluid content of 
sodium hyaluronate and proteoglycans in normal equine joints. Zentralbl Veterinarmed A 1993;40:10-6.

[111] Barr ARS, Duance VC, Wotton SF, Waterman AE. Influence of intra-articular sodium hyaluronate and polysulphated glycosaminoglycans on the biochemical composition of equine articular surface repair tissue. Equine Vet J 1994;26:40-2.

[112] Kawcak CE, Frisbie DD, Trotter GW, McIlwraith CW, Gillette SM, Powers BE, et al. Effects of intravenous administration of sodium hyaluronate on carpal joints in exercising horses after arthroscopic surgery and osteochondral fragmentation. Am J Vet Res 1997; 58:1132-40.

[113] Calder PC, Zurier RB. Polyunsaturated fatty acids and rheumatoid arthritis. Curr Opin Clin Nutr Metab Care 2001;4:115-21.

[114] Fortin PR, Lew RA, Liang MH, Wright EA, Beckett LA, Chalmers TC, et al. Validation of a meta-analysis: the effects of fish oil in rheumatoid arthritis. J Clin Epidemiol 1995;48: 1379-90.

[115] Anderson MA. Oral chondroprotective agents. Part II. Evaluation of products. Compend Contin Educ Pract Vet 1999;21:861-5.

[116] McCann ME, Carrick JB. Potential uses of $\omega-3$ fatty acids in equine diseases. Compend Contin Educ Pract Vet 1998;20:637-41.

[117] Halpern GM. Anti-inflammatory effects of a stabilized lipid extract of Perna canaliculus (Lyprinol). Allerg Immunol 2000;32:272-8.

[118] Canapp SO, McLaughlin RM, Hoskinson JJ, Roush JK, Butine MD. Scintigraphic evaluation of dogs with acute synovitis after treatment with glucosamine hydrochloride and chondroitin sulfate. Am J Vet Res 1999;60:1552-7.

[119] DiPadova C. S-adenosylmethionine in the treatment of osteoarthritis, review of the clinical studies. Am J Med 1987;83:60-5.

[120] Konig B. A long-term (2 year) clinical trial with S-adenosylmethionine for the treatment of osteoarthritis. Am J Med 1987;83:89-4.

[121] Bradley JD, Flusser D, Katz BP, Schumacher Jr HR, Brandt KD, Chambers MA, et al. A randomized, double blind, placebo controlled trial of intravenous loading with Sadenosylmethionine (SAM) followed by oral SAM therapy in patients with knee osteoarthritis. J Rheumatol 1994;21:905-11.

[122] Brandt KD. Second-line drug therapy for osteoarthritis. Clin Med 2001;1:110-4.

[123] Fernandes JC, Martel-Pelletier J, Jovanovic D, Tardif G, DiBattista JA, Lascau-Coman V, et al. The effects of tenidap on canine experimental osteoarthritis: II. Study of the expression of collagenase-1 and interleukin $1 \beta$ by in situ hybridization. J Rheumatol 1998;25:951-8.

[124] Pelletier JP, Jovanovic DV, Lascau-Coman V, Fernandes JC, Manning PT, Connor JR, et al. Selective inhibition of inducible nitric oxide synthase reduces progression of experimental osteoarthritis in vivo: possible link with the reduction in chondrocyte apoptosis and caspase 3 level. Arthritis Rheum 2000;43:1290-9.

[125] Jauering S, Schweighauser A, Reist M, Von Rechenberg B, Schawalder P, Spreng D. The effects of doxycycline on nitric oxide and stromelysin production in dogs with cranial cruciate ligament rupture. Vet Surg 2001;30:132-9.

[126] Shlopov BV, Stuart JM, Gumanovskaya ML, Hasty KA. Regulation of cartilage collagenase by doxycycline. J Rheumatol 2001;28:835-42.

[127] Tilley BC, Alarcon GS, Heyse SP, Trentham DE, Neuner R, Kaplan DA, et al. Minocycline in rheumatoid arthritis. A 48-week, double-blind, placebo-controlled trial. Ann Intern Med 1995;15:81-9.

[128] Herrmann G, Steeger D, Klasser M, Wirbitzky J, Furst M, Venbrocks R, et al. Oxaceprol is a well-tolerated therapy for osteoarthritis with efficacy equivalent to diclofenac. Clin Rheumatol 2000;19:99-104.

[129] Veihelmann A, Hofbauer A, Refior HJ, Messmer K. Oxaceprol, an atypical inhibitor of inflammation, reduces leukocyte adherence in mouse antigen-induced arthritis. Acta Orthop Scand 2001;72:293-8. 
[130] Altman RD, Marcussen KC. Effects of a ginger extract on knee pain in patients with osteoarthritis. Arthritis Rheum 2001;44:2531-8.

[131] Appleboom T, Schuermans J, Verbruggen G, Henrotin Y, Reginster JY. Symptoms modifying effect of avocado/soybean unsaponifiables (ASU) in knee osteoarthritis. Scand J Rheumatol 2001;30:242-7.

[132] Little CV, Parsons T. Herbal therapy for treating osteoarthritis. Cochrane Database Syst Rev 2001;1:CD002947.

[133] Mardjuadi A, Dequeker J. Double-blind trial comparing bufexamac infiltrations with triamcinolone acetonide infiltrations in patients with peri-arthritis of the shoulder. Curr Med Res Opin 1978;5:401-6.

[134] Suominen MM, Tulamo R-M, Puupponen LM, Sankari SM. Effects of intra-articular injections of bufexamac suspension on amphotericin B-induced aseptic arthritis in horses. Am J Vet Res 1999;60:1467-73.

[135] Suominen MM, Tulamo R-M, Anttila MO, Sankari SM, Kiraly K, Lapvetelainen T, et al. Effects of intra-articular injections of bufexamac suspension in healthy horses. Am J Vet Res 2001;62:1629-35.

[136] Kranke B, Szolar-Platzer C, Komericki P, Derhaschnig J, Aberer W. Epidemiological significance of bufexamac as a frequent and relevant contact sensitizer. Contact Dermatitis 1997;36:212-5.

[137] Bragdon B, Bertone AL, Hardy J, Simmons EJ. Use of an isolated joint model to detect early changes induced by intra-articular injection of paclitaxel-impregnated polymeric microspheres. J Invest Surg 2001;14:169-82.

[138] Cordero JA, Alarcon L, Escribano E, Obach R, Domenech J. A comparative study of the transdermal penetration of a series of nonsteroidal antiinflammatory drugs. J Pharm Sci 1997;86:503-8.

[139] Li LC, Scudds RA, Heck CS, Harth M. The efficacy of dexamethasone iontophoresis for the treatment of rheumatoid arthritic knees: a pilot study. Arthritis Care Res 1996;9:126-32.

[140] Moore RA, Tramèr MR, Carroll D, Wiffen PJ, McQuay HJ. Quantitative systematic review of topically applied non-steroidal anti-inflammatory drugs. BMJ 1998;316: 333-8.

[141] Trotter GW. Polysulfated glycosaminoglycan (Adequan). In: McIlwraith CW, Trotter GW, editors. Joint disease in the horse. Philadelphia: WB Saunders; 1996. p. 270-80.

[142] Burba DJ, Collier MA, Default LE, Hanson-Painton O, Thompson Jr HC, Holder CL. In vivo kinetic study on uptake and distribution of intramuscular tritium-labeled polysulfated glycosaminoglycan in equine body fluid compartments and articular cartilage in an osteochondral defect model. J Equine Vet Sci 1993;13:696-703.

[143] Sevalla K, Todhunter RJ, Vernier-Singer M, Budsberg SC. Effect of polysulfated glycosaminoglycan on DNA content and proteoglycan metabolism in normal and osteoarthritic canine articular cartilage explants. Vet Surg 2000;29:407-14.

[144] Glade MJ. Polysulfated glycosaminoglycan accelerates net synthesis of collagen and glycosaminoglycans by arthritic equine cartilage tissues and chondrocytes. Am J Vet Res 1990;51:779-85.

[145] Yovich JV, Trotter GW, McIlwraith CW, Norrdin RW. Effects of polysulfated glycosaminoglycan on chemical and physical defects in equine articular cartilage. Am J Vet Res 1987;48:1407-14.

[146] Todhunter RJ, Yeager AE, Freeman KP, Parente EJ, Lust G. Keratan sulfate as a marker of articular cartilage catabolism and joint treatment in ponies. Am J Vet Res 1993;54: $1007-16$.

[147] Todhunter RJ, Minor RR, Wootton JAM, Krook L, Burton-Wurster N, Lust G. Effects of exercise and polysulfated glycosaminoglycan on the repair of articular cartilage defects in the equine carpus. J Orthop Res 1993;11:782-95.

[148] Todhunter RJ, Lust G. Polysulfated glycosaminoglycan in the treatment of osteoarthritis. JAVMA 1994;204:1245-51. 
[149] Todhunter RJ, Freeman KP, Yeager AE, Lust G. Effects of exercise and polysulfated glycosaminoglycan on the development of osteoarthritis in equine carpal joints with osteochondral defects. Vet Surg 1993;22:330-42.

[150] Crisman M, Furr M, Ley W, Flynn DV, Kenney JE. Evaluation of polysulfated glycosaminoglycan for the treatment of navicular disease: a double blind study. In: Proceedings of the 39th Annual Convention of the American Association of Equine Practitioners, San Antonio. Lexington (KY): American Association of Equine Practitioners; 1993. p. 219-20.

[151] Caron JP, Kaneene JB, Miller R. Results of a survey of equine practitioners on the use and perceived efficacy of polysulfated glycosaminoglycan. JAVMA 1996;209:1564-8.

[152] Little C, Ghosh P. Potential use of pentosan polysulfate for the treatment of equine joint disease. In: McIlwraith CW, Trotter GW, editors. Joint disease in the horse. Philadelphia: WB Saunders; 1996. p. 281-92.

[153] Deal CL, Moskowitz RW. Nutraceuticals as therapeutic agents in osteoarthritis. The role of glucosamine, chondroitin sulfate, and collagen hydrolysate. Rheum Dis Clin North Am 1999;25:379-95.

[154] Karzel K, Domenjoz R. Effects of hexosamine derivatives and uronic acid derivatives on glycosaminoglycan metabolism of fibroblast cultures. Pharmacology 1971;5:337-45.

[155] Anderson CC, Cook JL, Kreeger JM, Tomlinson JL, Wagner-Mann CC. In vitro effects of glucosamine and acetylsalicylate on canine chondrocytes in three-dimensional culture. Am J Vet Res 1999;60:1546-51.

[156] Anderson MA. Oral chondroprotective agents. Part I. Common compounds. Compend Contin Educ Pract Vet 1999;21:601-9.

[157] Conte A. Biochemical and pharmacokinetic aspects of oral treatment with chondroitin sulfate. Arzniemttelforschung 1995;45:918-25.

[158] Davidson G. Glucosamine and chondroitin sulfate. Compend Contin Educ Pract Vet 2000;22:454-8.

[159] Dorna V, Guerrero RC. Effects of oral and intramuscular use of chondroitin sulfate in induced equine aseptic arthritis. J Equine Vet Sci 1999;19(Suppl 1):14-8.

[160] Hanson RR, Brawner WR, Blaik MA, Hammad TA, Kincaid SA, Pugh GH. Oral treatment with a nutraceutical (Cosequin $\AA$ ) for ameliorating signs of navicular syndrome in horses. Vet Ther 2001;2:148-59.

[161] Hanson RR, Smalley LR, Huff GK, White S, Hammad TA. Oral treatment with a glucosamine-chondroitin sulfate compound for degenerative joint disease in horses: 25 cases. Equine Pract 1997;19:16-22.

[162] White GW, Jones EW, Hamm J, Sanders T. The efficacy of orally administered sulfated glycosaminoglycan in chemically induced equine synovitis and degenerative joint disease. J Equine Vet Sci 1994;14:350-3.

[163] Anderson MA, Slater MR, Hammad TA. Results of a survey of small-animal practitioners on the perceived clinical efficacy and safety of an oral nutraceutical. Prev Vet Med 1999;38:65-73.

[164] McNamara PS, Barr SC, Erb H, Barlow LL. Hematologic, hemostatic, and biochemical effects in cats receiving an oral chondroprotective agent for 30 days. Vet Ther 2000;1: $108-17$.

[165] Kirker-Head CA, Kirker-Head RP. Safety of an oral chondroprotective agent in horses. Vet Ther 2001;2:345-53.

[166] Rejholec V. Long-term studies of antiosteoarthritic drugs: an assessment. Semin Arthritis Rheum 1987;17(Suppl 1):35-53.

[167] Boothe DM. Nutraceuticals in veterinary medicine. Part II. Safety and efficacy. Compend Contin Educ Pract Vet 1998;20:15-21.

[168] Horstman J. The arthritis foundation's guide to alternative therapies. Atlanta: The Arthritis Foundation; 1999. p. 179-80. 
[169] Hwa SY, Burkhardt D, Little C, Ghosh P. The effects of orally administered diacerein on cartilage and subchondral bone in an ovine model of osteoarthritis. J Rheumatol 2001; 28:825-34.

[170] Tamura T, Kosaka N, Ishiwa J, Sato T, Nagase H, Ito A. Rhein, an active metabolite of diacerein, down-regulates the production of pro-matrix metalloproteinases-1, $-3,-9$ and -13 and up-regulates the production of tissue inhibitor of metalloproteinase- 1 in cultured rabbit articular chondrocytes. Osteoarthritis Cartilage 2001;9:257-63.

[171] Tamura T, Ohmori K. Diacerein suppresses the increase in plasma nitric oxide in rat adjuvant-induced arthritis. Eur J Pharmacol 2001;419:269-74.

[172] Dougados M, Nguyen M, Berdah L, Mazieres B, Vignon E, Lequesne M. Evaluation of the structure-modifying effects of diacerein in hip osteoarthritis: ECHODIAH, a threeyear, placebo-controlled trial. Evaluation of the chondromodulating effect of diacerein in OA of the hip. Arthritis Rheum 2001;44:2539-47.

[173] Nicholas P, Tod M, Padoin C, Petitjean O. Clinical pharmacokinetics of diacerein. Clin Pharmacokinet 1998;35:347-59.

[174] Frisbie DD, Trotter GW, Powers BE, Rodkey WG, Steadman JR, Howard RD, et al. Arthroscopic subchondral bone plate microfracture technique augments healing of large chondral defects in the radial carpal bone and medial femoral condyle of horses. Vet Surg 1999;28:242-55.

[175] Hurtig M, Pearce S, Warren S, Kalra M, Miniaci A. Arthroscopic mosaic arthroplasty in the equine third carpal bone. Vet Surg 2001;30:228-39.

[176] McIlwraith CW, Nixon AJ. Joint resurfacing: attempts at repairing articular cartilage defects. In: McIlwraith CW, Trotter GW, editors. Joint disease in the horse. Philadelphia: WB Saunders; 1996. p. 317-34.

[177] Frisbie DD, McIlwraith CW. Evaluation of gene therapy as a treatment for equine traumatic arthritis and osteoarthritis. Clin Orthop 2000;379(Suppl):S273-87.

[178] Harman JC. Complementary (alternative) therapies for poor performance, back problems and lameness. In: Robinson NE, editor. Current therapy in equine medicine. 4th edition. Philadelphia: WB Saunders; 1997. p. 131-7.

[179] Blake DJ, Maisiak R, Koplan A, Alarcon GS, Brown S. Sexual dysfunction among patients with arthritis. Clin Rheumatol 1988;7:50-60.

[180] Smilack JD. The tetracyclines. Mayo Clin Proc 1999;74:727-9.

[181] Crisman MV, Wilcke JR, Sams RA, Gerken DF. Concentrations of phenylbutazone and oxyphenbutazone in post-parturient mares and their neonatal foals. J Vet Pharmacol Ther 1991;14:330-4.

[182] Clark JO, Clark TP. Analgesia. Vet Clin North Am Equine Pract 1999;15:705-23.

[183] Crisman MV, Sams RA, Irby MH. The disposition of phenylbutazone in lactating mares and its effect on nursing foals. In: Proceedings of the 35th Annual Convention of the American Association of Equine Practitioners, Boston. Lexington (KY): American Association of Equine Practitioners; 1989. p. 127-31.

[184] Dubois RN, Abramson SB, Crofford L, Gupta RA, Simm LS, Van De Putte LB, et al. Cyclooxygenase in biology and disease. FASEB J 1998;12:1063-73. 